\title{
Globalização e desafios urbanos: Políticas públicas e desigualdade social nas cidades brasileiras
}

\section{Margaretb de C. Afeche Pimenta}

Professora do Departamento de Arquitetura e Urbanismo, do Programa de Pós-

Graduação em Urbanismo, História e Arquitetura da Cidade, e do Programa de PósGraduação em Geografia da Universidade Federal de Santa Catarina, Brasil. Mestre pela COPPE-UFRJ e Doutora pela Universidade de Paris IV-Sorbonne.

\section{Luís Fugazzola Pimenta}

Professor do Departamento de Arquitetura e Urbanismo da Universidade Federal de Santa Catarina, Brasil. Mestre pela COPPE-UFRJ.

RESUMEN | Os diversos ciclos de crescimento econômico evitaram uma redistribuição mais equitativa da riqueza, agravando as desigualdades sociais e empobrecendo as populações urbanas brasileiras. Essa herança histórica agrava-se, no presente, pela escamoteação do papel do Estado, substituindo o caráter universal dos direitos sociais - destacando-se os serviços essenciais como educação e saúde - por procedimentos ocasionais e corporativos respondendo, de forma subalterna, às exigências do novo período de acumulação mundial. Somando-se à precariedade histórica, o abandono ou a privatização dos serviços públicos acompanha o novo ciclo de desemprego, explícito ou dissimulado, permitindo que o Estado contribua para o reforço da pobreza e da exclusão social. A paisagem retratará a polarização das classes sociais fazendo conviver locais de representação da sofisticação supérflua com a banalização da reprodução da vida. A metrópole transforma-se em seu contrário: de veículo de penetração de inovações e de crescimento cultural transmuta-se em cenário do medo e do antagonismo social.

PALABRAS CLAVE | Desigualdade social, pobreza, política urbana.

ABSTRACT | Several cycles of economic growth avoided a fairer distribution of wealth, exacerbating social inequalities and increasing poverty of urban populations in Brazil. This heritage is worsened in the present by the diminishing role of the state, replacing the universal character of social rights - most importantly essential services like education and health - for casual and corporate procedures that respond, in a subordinate way, to the demands of the new period of global accumulation. Adding to the historic instability, the abandonment or privatization of public services is accompanied by a new cycle of unemployment, explicit or hidden, that allows the state to contribute to the strengthening of poverty and social exclusion. This text portrays the polarization of social classes by the cohabitation of places of superfluous sophistication representations with the trivialization of life reproduction. The metropolis turns into its opposite: from a position of vehicle for innovations and cultural growth it transmutes into a scenery offear and social antagonism.

KEY WORDS | Social inequality, poverty, urban policy.

Recibido el 14 de abril de 2009, aprobado el 16 de mayo de 2011.

Agradecemos ao CNPq, Conselho Nacional de Desenvolvimento Científico e Tecnológico, Brasil, que financiou as pesquisas das quais este artigo é um dos resultados.

Correspondencia: Departamento de Arquitetura e Urbanismo - Centro Tecnológico, Universidade Federal de Santa Catarina, Campus Universitário Trindade, 88040-900 Florianópolis/Santa Catarina, Brasil. Margareth de C. Afeche Pimenta, e-mail: pimenta.margareth@gmail.com | Luís Fugazzola Pimenta, e-mail: lpimenta@arq.ufsc.br 


\section{Introdução}

Os países da América Latina, de diferentes maneiras, conheceram diversos ciclos de crescimento econômico sem, no entanto, amenizarem as precárias condições de vida e a falta de acessibilidade aos serviços elementares, indispensáveis ao desenvolvimento social. O Brasil, mesmo figurando entre as maiores nações em termos de geração de riqueza desde os anos 1980, continua a revelar elevados índices de desigualdade social, sem apresentar qualquer delineamento de políticas que possa reverter os rumos até então adotados, no sentido da construção de uma sociedade mais equitativa.

Se nos períodos de crescimento econômico fez-se presente somente uma vaga promessa de repartição posterior dos frutos da riqueza ${ }^{1}$, a crise subseqüente veio agravar os sérios problemas sociais concernentes à falta das condições mínimas para a reprodução da vida. Paradoxalmente, são Governos considerados democráticos que contribuem, a partir da inserção submissa ao capital financeiro internacional, para o aprofundamento da sociedade desigual. A crise, trazendo consigo a fragilização dos vínculos empregatícios e o desemprego, veio se somar à herança de um mercado de trabalho amplamente baseado no setor informal, onde grandes parcelas da população já se encontravam excluídas das poucas proteções sociais existentes. Os governos que se sucederam após os anos 1980, nada mais fizeram que retirar dos trabalhadores os já frágeis direitos sociais que haviam sido outorgados no governo do Presidente Getúlio Vargas a partir dos anos $1930^{2}$. Período em que o Estado intervém na regulação entre as relações capital-trabalho por ocasião da constituição do mercado nacional unificado, no sentido de priorizar os interesses do capital industrial (Oliveira, 1982). Nos diferentes ciclos de crescimento econômico não houve correspondência de políticas de cunho social, ficando os sucessivos Governos restritos à adoção de medidas de regulação dos mercados de trabalho e de consumo (Bolaffi, 1982).

À instabilidade empregatícia dos anos 1990 soma-se a falta de políticas efetivas de redistribuição da renda e de criação de oportunidades de superação das desigualdades sociais. Medidas assistencialistas, de caráter puramente imediato, não podem ser consideradas substitutivas das políticas sociais, as únicas capazes de gerar condições para a superação das desigualdades sociais, pressuposto fundamental para a constituição de uma sociedade de direitos. São os serviços públicos elementares (educação e saúde, principalmente), concebidos como direitos universais, que podem criar as condições de ruptura desse processo histórico de ampliação das desigualdades sociais. Relações clientelistas tendem a se retroalimentar pela coni-

1 Conforme promessa de Delfim Neto, então Ministro do Governo Garrastazu Médici, seriam necessários sacrifícios para se alcançar as taxas de crescimento de meados da década de 1970, ou seja, o "bolo" precisava primeiro crescer para poder ser partilhado posteriormente. Delfim Neto continua por aqui, sendo ouvido pelos sucessivos governantes, mas sem se sentir obrigado a responder pela repartição prometida.

2 A CLT (Consolidação das Leis do Trabalho), instituída em 1943 unifica a legislação trabalhista e vem se seguir à criação da Justiça do Trabalho em 1939. No primeiro Governo Vargas já havia sido estabelecida a Carteira de Trabalho e a sindicalização, primeiros passos no sentido de regulamentação da força de trabalho. (Fausto, 1978) 
vência entre os interesses em jogo e, por isso, necessitam que as poucas mudanças introduzidas sejam sempre no sentido da permanência das dependências e dos favores. Para que essas relações assimétricas se estabeleçam, faz-se necessário manter a estrutura da pirâmide social o mais imutável possível, perpetuando a diferenciação social. A sociedade dual passa a ser uma característica constante ${ }^{3}$, contrapondo as diferenças a partir da extremada concentração da renda, o que vem fragilizar a possibilidade de construção de uma sociedade de direitos. A paisagem fica, então, marcada pela convivência explícita dos signos ostentatórios da riqueza (Veblen, 1970) com a rudeza das dificuldades de reprodução da vida cotidiana.

Assim, esse início de século XXI coloca para as metrópoles e para as grandes cidades brasileiras - aquelas que são o destino privilegiado dos destituídos que procuram suas estratégias de sobrevivência ao lado da riqueza concentrada - o desafio de superar as enormes desigualdades sociais que se desenham nos cenários urbanos. A fragmentação espacial, a paisagem desigual e a violência urbana demonstram que a sociedade se bipolariza e, com isso, as possibilidades de convívio se amesquinham.

\section{Ciclos de crescimento e desigualdades sociais no Brasil}

Ao longo da história de seu processo de industrialização desde meados do século XIX, o Brasil construiu um parque fabril dinâmico e diversificado. Realizou este percurso a partir da industrialização "em ordem inversa" - da produção de bens de consumo não-duráveis até bens de produção (Rangel, 1982) - utilizando-se do processo de substituição gradativa de importações (Tavares, 1981, 1985). Assim, conseguiu mudar sua posição de fornecedor mundial de produtos primários a exportador de manufaturados graças, sobretudo, à política de incentivos governamentais instituída após a década de 1970 . Os constantes ciclos renovadores da economia, baseados na superação dos atrasos relativos e no uso das potencialidades em termos de recursos e mercado interno, fizeram o Brasil crescer a taxas médias superiores a 7\% ao ano após a Segunda Guerra Mundial, alcançando índices invejáveis no decorrer dos anos 70 (em torno de 10\% a 11\% ao ano) (Batista Júnior, 2000). Os sucessivos planos econômicos estabelecidos durante os anos 1980 - a "década perdida" - não conseguiram reverter a crise fiscal do Estado e sua incapacidade de saldar os compromissos internacionais assumidos. Baseados em fluxos voláteis ou de curto prazo, significavam agora restrições consideráveis aos gastos governamentais em setores onde a dívida social vinha historicamente agravando-se, transformando o Brasil num dos países mais desiguais do mundo.

A hegemonia americana - fortalecida após a queda do muro de Berlim e a dissolução da União Soviética - impõe modelos generalizantes aos países latino-americanos, baseados na alta dos juros e valorização cambial - o que torna os produtos

O fato de caracterizar a sociedade como polarizada em sua desigualdade social e, portanto, dual, não necessariamente significa a existência de circuitos independentes - ou seja, não contradiz a "Crítica à Razão Dualista" de Oliveira (1972) -, mas pretende acrescentar a idéia de uma pirâmide social descontínua e fragmentada, conforme concepção de Santos (1979). Pode-se considerar, assim, uma sociedade desigual e combinada, conforme a crítica de Trostsky (2007) à III Internacional, já transformada pelo Stalinismo. 
menos competitivos internacionalmente -, na deflação e no desemprego (Tavares, 1999). O Brasil foi um dos últimos países a se adaptar à nova lógica da globalização financeira, adotando a política de liberalização comercial e financeira no sentido de atrair recursos externos. Cativo de compromissos financeiros internacionais, o Estado brasileiro permitiu um processo de desnacionalização e desorganização do seu parque industrial, além de um rebaixamento das condições de competitividade internacional dos produtos nacionais. As privatizações realizadas em nome do saneamento das finanças públicas restringiram-se à transferência patrimonial, sem aumento substantivo do parque industrial já instalado (Tavares, 2000). A abertura indiscriminada do mercado nacional - exercida pelo imperativo dos princípios neoliberais e pelo discurso globalizante - levou à rápida reversão de uma história de crescimento contínuo e promissor, provocando processos de crise e de desnacionalização de empresas tradicionais devido à ação combinada entre necessidade de modernização e insolvência financeira (Castro, 2000).

A globalização perversa, baseada na democracia de mercado e no neoliberalismo, assim como na transnacionalização do território - acomodando tanto a escala técnica como política do território, ao novo ciclo de acumulação mundial - define, a partir da mediação do Estado Nacional, uma política econômica baseada no ajustamento aos critérios produtivos e creditícios das grandes corporações internacionais (Santos, 1994). A solidariedade das mutações no plano mundial é, assim, "em grande parte, administrada” (Santos, 1991, p. 11). O Estado nacional, representado sobretudo pelos governos eleitos a partir do início dos anos 1990, comportou-se como um elo neste processo de adaptação da economia nacional, permitindo ou mesmo estimulando a desnacionalização do parque fabril, desviando recursos da pesquisa científica e tecnológica e condenando o Brasil à exportação de commodities (Castro, 2000b). Permite, assim, um aumento da defasagem tecnológica e produtiva, abandonando qualquer projeto nacional de desenvolvimento (Tavares, 2001).

Contrariamente aos períodos anteriores, a crise que se agrava promove a urbanização sem crescimento, herança de conjuntura política global, que inclui a crise mundial da dívida externa do final da década de 1970, e a subseqüente reestruturação das economias do Terceiro Mundo sob a liderança do FMI nos anos 1980 (Davis, 2006). O mundo conhece uma urbanização continuada apesar da queda do salário real, da alta dos preços e da disparada do desemprego urbano a partir da década de 1990, promovendo uma perversa expansão urbana. A pobreza de novo tipo, sem esperanças de superação de sua condição, varia, no entanto, segundo a qualidade da intervenção do Estado. Contrariamente ao preconizado pelos interesses do capital financeiro internacional - através de seus interlocutores, no caso, o FMI e o Banco Mundial -, não foram os países que submeteram seus Estados à lógica da globalização aqueles que obtiveram êxito nos processos de desenvolvimento nacional. Países dirigistas (como a China, por exemplo) ou fortemente protecionistas (como países europeus) lograram um crescimento econômico e tecnológico acelerado, expandindo seus mercados interiores, elevando a renda interna. Em contrapartida, o privilégio atribuído ao superávit primário, sacrificando todas 
as medidas de caráter social efetivamente transformadoras da pirâmide social, levou à extensão inusitada da pobreza. Isso é o que se assiste no Brasil, sobretudo, a partir da década de 1990.

A falta ou precariedade dos serviços públicos, que foram herdadas historicamente, vem se agravar, no momento presente, pela escamoteação do papel do Estado, substituindo a noção de políticas públicas por intervenções setoriais, segmentadas e assistencialistas. Substitui-se assim, o caráter universal dos direitos sociais por procedimentos ocasionais e corporativos que respondem, de forma subalterna, às exigências do novo ciclo mundial de acumulação. Num país que necessita resolver graves problemas sociais, um projeto nacional de desenvolvimento precisa considerar a importância dos serviços básicos de educação e saúde como alicerces para superação do atraso a que estão submetidas amplas parcelas da população.

\section{Os serviços urbanos de educação e saúde}

Se Deus não existe, se a ONU se cala, se os governos se entregam, se os hospitais adoentam e se as escolas deseducam, as serpentes rompem seus ovos... (Boal, 2002).

O pós-guerra expande, mundialmente, o ideário de uma sociedade de direitos universais assegurados pelo Estado. Na Declaração Universal dos Direitos Humanos figura, explicitamente, o direito à seguridade social (Artigo 22), aos cuidados médicos e à proteção na velhice ou por invalidez (Artigo 25), à educação gratuita e ao ensino fundamental obrigatório, complementado, ainda, pela oportunidade ao ensino técnico e profissional e ao acesso aos estudos superiores em plena igualdade em função dos méritos pessoais (Artigo 26) (Nações Unidas, 1948).

Nas finalidades do serviço público distinguem-se três tipos de funções: assegurar uma prestação de serviço (bens materiais, equipamentos e obras, prestações monetárias e não-monetárias); operar certa redistribuição territorial (homogeneização - planejamento do território nacional) ou social (transferência entre grupos ou indivíduos) e impor diversas formas de constrangimento social (para garantir os "bens coletivos" como segurança, salubridade, saúde pública, etc.). Nos serviços públicos sociais a função de redistribuição é central, a prestação e o constrangimento devem estar ausentes (Lafore, 1999, p. 375).

No Brasil, como em outros países subdesenvolvidos, a proteção social sempre apresentou características bastante restritas. Apesar de ter avançado no processo de industrialização, sobretudo a partir da década de 30, o Brasil não superou disparidades regionais e setoriais, a desigual distribuição e a elevada concentração de ren$\mathrm{da}$, assim como a decorrente precariedade das condições de vida e de trabalho. $\mathrm{O}$ sistema de proteção social ganhou impulso a partir dos anos 30, ficando, até então, os custos da reprodução da força de trabalho embutidos na estrutura da produção (Carone, 1974). A legislação social e trabalhista estabelecida na "Consolidação das Leis do Trabalho" beneficiava principalmente os trabalhadores assalariados com Carteira assinada, em geral trabalhadores urbanos, excluindo a maioria da popu- 
lação que vivia no campo. Instala-se, assim, um sistema de proteção social meritocrático e particularista, pois privilegiava somente parte da população. A maioria da população, além de não estar incluída na regulamentação do salário mínimo e dos direitos trabalhistas, ficava desamparada em termos de serviços elementares (Pochmann, 2004).

A estrutura tributária implantada para viabilizar o regime de proteção social era particularmente dependente de impostos e contribuiçôes sobre o custo do trabalho, o que onerava justamente a renda dos mais pobres. $\mathrm{O}$ financiamento da proteção social representava " $1 / 3$ do custo total do empregado urbano, o que tornou o acesso ao contrato formal de trabalho mais difícil e um problema para o acesso e difusão de uma cidadania de natureza regulada” (Pochmann, 2004).

A perpetuação de relações não-capitalistas e do trabalho informal no Brasil impulsionou estratégias de sobrevivência fora de um sistema efetivo de inserção social, o que não veio a se constituir como uma necessidade do processo de acumulação ou uma real preocupação dos diferentes Governos que se sucederam, principalmente no grande ciclo de crescimento do pós-guerra (Oliveira, 1982). A Constituição de 1988, ainda em vigor, preconiza a extensão dos benefícios para trabalhadores rurais e urbanos, a obrigatoriedade do ensino público gratuito e a extensão do sistema de saúde, sem que, no entanto, medidas nesse sentido tenham sido realmente efetivadas. O processo de desorganização do Estado no Brasil, instituído a partir dos anos 80 e principalmente decorrente da inserção submissa na economia mundial após os anos 90, apóia-se, sobretudo, na idéia de diluição da responsabilidade do Estado em relação à universalização dos serviços públicos elementares.

Se o Brasil jamais conheceu um sistema de proteção social universalista -como o implantado pelos países desenvolvidos sob o regime do Welfare State (Merrien, 1997)-, a década de 90 retirando direitos sociais dos trabalhadores, promovendo a queda sistemática da capacidade aquisitiva e estimulando relações de trabalho precárias e instáveis (Harvey,1992) não fez mais do que acentuar, contrariamente ao preconizado, a importância do papel dos serviços públicos gratuitos e universais, no sentido de manter a qualidade de vida das populações. Medidas assistenciais (como bolsa família, por exemplo) e políticas setorizadas (como as políticas ditas compensatórias) não são mais que arremedos, cujo sentido está mais voltado à constituição de uma ampla rede eleitoral, do que ao resgate da dívida histórica de formação de uma sociedade nacional calcada em princípios de direitos igualitários.

\section{Um sistema educacional formal, sem ser efetivo}

Sem querer esgotar a abordagem do problema, alguns indicadores tornam-se, em si mesmos, bastante expressivos para assinalar o quadro de precariedade que o país ainda atravessa em questões de ensino, sem conseguir equacionar antigas lacunas educacionais (Beisegel, 1984). O Brasil ainda contava, em 2007, com 14,1 milhões de analfabetos entre as pessoas de 15 anos ou mais de idade (10,0\% do setor). Embora entre as crianças e adolescentes de 7 a 14 anos de idade, faixa etária correspon- 
dente ao ensino fundamental, o ensino esteja praticamente universalizado ( $97,6 \%$ são considerados freqüentadores), os resultados da pesquisa mostram que este alto índice de suposto comparecimento à escola nem sempre se traduz em qualidade do aprendizado. Dados comparativos referentes ao atraso escolar colocam o Brasil em uma posição pouco confortável entre os países da América Latina e do Caribe (Quadro 1).

QUADRO 1 | Cobertura das oportunidades básicas em educação em 2005

\begin{tabular}{|c|c|c|}
\hline & $\begin{array}{c}\text { SEXTA SÉRIE NO DEVIDO } \\
\text { TEMPO (\%) }\end{array}$ & ASSISTÊNCIA ESCOLAR (\%) \\
\hline JAMAICA & 88 & 95 \\
\hline MÉXICO & 88 & 95 \\
\hline ARGENTINA & 85 & 96 \\
\hline CHILE & 83 & 99 \\
\hline URUGUAI & 81 & 96 \\
\hline EQUADOR & 81 & 89 \\
\hline PERU & 79 & 96 \\
\hline VENEZUELA & 78 & 96 \\
\hline BOLÍVIA & 78 & 95 \\
\hline PANAMÁ & 77 & 94 \\
\hline COLÔMBIA & 76 & 91 \\
\hline COSTA RICA & 72 & 94 \\
\hline REP. DOMINICANA & 66 & 97 \\
\hline PARAGUAI & 66 & 92 \\
\hline HONDURAS & 54 & 84 \\
\hline EL SALVADOR & 51 & 90 \\
\hline BRASIL & 47 & 97 \\
\hline NICARÁGUA & 44 & 88 \\
\hline GUATEMALA & 33 & 81 \\
\hline
\end{tabular}

FONTE ELABORAdo PELOS AUTOREs, A PARTir de BARros E oUtros, 2008, P.89.

Além da defasagem escolar, o Brasil possui um sistema educacional que, muitas vezes, não faz aprender, apesar dos estudantes irem avançando nas séries escolares. Entre as 28,3 milhões de crianças de 7 a 14 anos, que pela idade já teriam passado pelo processo de alfabetização, foram encontradas 2,4 milhões $(8,4 \%)$ que não sabem ler e escrever, sendo que 2,1 milhões delas, $(87,2 \%)$ freqüentavam estabelecimentos de ensino. Aos 14 anos, idade em que se deveria concluir o ensino 
fundamental, conta-se 58,1 mil pessoas que não sabem sequer assinar o próprio nome. Esse dado poderia ser considerado inadmissível em qualquer país que encarasse seriamente a educação, já que quase metade destas pessoas $(45,8 \%)$ estava na escola em 2007 (IBGE, 2008).

Agrupando-se o número de analfabetos absolutos (7\%) e alfabetizados em nível rudimentar (25\%) obtém-se o índice de analfabetos funcionais ${ }^{4}$ que, no Brasil, atinge 32\% entre crianças e adolescentes de 7 a 14 anos (Ibope, 2007). Na Alemanha, a taxa de analfabetos funcionais é de 14\%, nos EUA, 21\%, na Suécia é de $7 \%$. Estudantes da classe média brasileira lêem pior do que operários alemães. No Brasil, a média anual de leitura por habitante é de 1,8 livros, contra 7 da França, 5,1 dos Estados Unidos, 5 da Itália e 4,9 livros da Inglaterra (Tiezzi, 2008). Em todas as nações desenvolvidas, ou que têm a pretensão de sê-lo, a formação escolar conta como requisito primordial. Mesmo sem considerar razões de ordem social, o período técnico-científico atual, onde a ciência constitui-se em força produtiva direta (Braverman, 1981), a elevação do nível educacional implica imediatamente nas possibilidades do próprio crescimento econômico nacional.

O rendimento familiar é importante na questão do analfabetismo. No conjunto da população que vivia com rendimento familiar per capita de até meio salário mínimo, cerca de $18 \%$ eram analfabetos em 2007; já nas classes de rendimentos superiores a dois salários mínimos, o percentual era de 1,4\%. As classes médias fogem para o sistema educacional privado, procurando oportunizar o futuro das novas gerações. Os mais empobrecidos têm, portanto, suas chances diminuídas, já que ficam cativos do ensino de baixa qualidade patrocinado pelo Estado. Chama também atenção o número de crianças de 14 anos que estão fora da escola (cerca de 204.800 crianças), o que, em geral, está associado à prematura inserção no mercado de trabalho ou em serviços domésticos (IBGE, 2008). Manter as crianças na escola também deveria se constituir em tarefa do Estado.

Assim como a classe social e a renda são elementos decisivos nas possibilidades educacionais - tendo em vista a debilidade das intervenções estatais -, as desigualdades regionais também pesam em relação às chances de superação das condições de pobreza. Em todos os indicadores que possam ser considerados, as disparidades maiores sempre estão presentes no Norte e no Nordeste do país, onde os ingressos são menores e as dificuldades de acesso aos serviços educacionais são maiores.

Se existe uma relação direta entre a distribuição da renda e as oportunidades no território nacional, o mesmo não se pode dizer em termos mundiais. Aqui, as políticas públicas das diferentes nações incidem diferentemente sobre as questões econômicas e sociais. Não existe uma relação direta entre PIB per capita e alfabetização, o que indica a importância das opções políticas dos diferentes governos nacionais. O Brasil, que possui um dos maiores PIBs mundiais (o $9^{\circ} \mathrm{em} 1^{\circ}$ de janeiro de 2008, segundo dados do Banco Mundial) não apresenta resultados concordantes no plano educacional. Mesmo se a comparação se der dentro da América Latina,

4 É considerada analfabeta funcional a pessoa que, mesmo sabendo ler e escrever, não tem habilidades de leitura, de escrita e de cálculo necessárias para viabilizar seu desenvolvimento pessoal ou profissional (Ibope, 2007). 
o Brasil fica em posição desfavorável frente a países que possuem PIB per capita inferior ao brasileiro (Quadro 2).

QUADro 2 | Alfabetização e PIB per capita na América do Sul e Central

\begin{tabular}{|c|c|c|c|c|c|}
\hline & $\begin{array}{c}\text { TAXA DE } \\
\text { ALFABETIZAÇÃO } \\
(\%)\end{array}$ & & & PIB PER CAPITA (U\$) & \\
\hline POSIÇÃo & PAÍS & VALOR & POSIÇÃa & PAÍS & VALOR \\
\hline 6 & Cuba & 100 & 60 & Porto Rico & 19,6 \\
\hline 41 & Uruguai & 98 & 75 & Chile & 14,4 \\
\hline 43 & Guiana & 98,5 & 78 & Costa Rica & 13,5 \\
\hline 53 & Argentina & 97 & 80 & Argentina & 13 \\
\hline 59 & Costa Rica & 96 & 81 & Venezuela & 12,8 \\
\hline 63 & Chile & 96 & 83 & México & 12,5 \\
\hline 67 & Porto Rico & 94 & 90 & Uruguai & 10,7 \\
\hline 73 & Paraguai & 93 & 95 & Brasil & 9,7 \\
\hline 75 & Venezuela & 93 & 98 & Rep. Dominicana & 9.200 \\
\hline 76 & Colômbia & 93 & 101 & Panamá & 9 \\
\hline 79 & Jamaica & 92 & 108 & Suriname & 7,8 \\
\hline 81 & Panamá & 91 & 111 & Peru & 7,6 \\
\hline 87 & Equador & 90 & 113 & Colômbia & 7,2 \\
\hline 88 & México & 90 & 114 & Equador & 7,1 \\
\hline 91 & Brasil & 89 & 126 & Guatemala & 5,4 \\
\hline
\end{tabular}

EM ITÁlICO, OS PAÍSES QUE POSSUEM UM PIB PER CAPITA MAIS BAIXO DO QUE O BRASILEIRO E, NO ENTANTO, APRESENTAM TAXAS DE ALFABETIZAÇÃO SUPERIORES 5 .

FONTE Elaborado a PARTIR de dados de CIA World FACTBOoK, 01 de JANEIRo de 2008.

Quando se atribui ao Brasil uma posição quase vexatória em relação ao cenário mundial em termos de educação, trata-se, em primeiro lugar, do ensino público oferecido pelo Estado. Tanto a persistência do analfabetismo como de crianças fora da escola, em estreita relação com o nível de renda, colocam ao Estado um papel decisivo na possibilidade de se romper o circuito da pobreza. Para isso, medidas assistenciais tornam-se inócuas se o Estado oferece uma escola de baixa qualidade com instalações precárias e professores mal remunerados. $\mathrm{O}$ descaso vai além da possibilidade de adquirir conhecimentos específicos e questiona a própria possibilidade de constituição da consciência de cidadania:

5 Todos os países em itálico possuem PIB total menor do que o brasileiro. PIB per capita de Cuba= U\$4500; Guiana= U\$5300; Paraguai $=$ U\$4000; Jamaica $=$ U\$4800. 
"Nas pesquisas internacionais sobre aprendizagem, a escola pública brasileira é muito mal posicionada, não corresponde ao nível econômico do país. O fosso entre a escola pública e a escola privada é um desafio para a democracia brasileira. O desafio é este: a escola pública vai poder assumir seu papel emancipador?" (Moignard, 2008) ${ }^{6}$.

Contrariamente ao preconizado nas Leis de Diretrizes e Bases (Brasil, 1996), as condições da educação nacional, restringindo a alfabetização real (aquela capaz de permitir a compreensão dos significados) em prol de resultados formais, colocam em cheque a possibilidade do exercício pleno da cidadania que supõe tomada de posições elucidadas e conscientes. Sem educação de qualidade a perspectiva brasileira volta-se à eternização da dependência clientelista em relação ao Estado, o que por sua vez acaba por dificultar o reconhecimento a direitos universais básicos. Se a educação for considerada como um fator importante na possibilidade de superação da pobreza e no acesso ao exercício efetivo da cidadania, o Brasil precisa rever rapidamente suas prioridades, ao menos para compatibilizar o discurso político governamental com a realidade cruamente apresentada pelos números das próprias estatísticas estatais e mundiais.

\section{Um sistema de saúde discricionário}

A situação atual do Brasil com relação à saúde é precária: poucas instalações, defasadas, com poucos equipamentos, número insuficiente de funcionários e de recursos. A transferência do encargo público para a iniciativa privada serviu para degradar ainda mais o sistema de saúde, oferecendo um serviço nem sempre condizente com os recursos implicados. Além do mais, os atendimentos mais custosos são ainda transferidos para o Estado, deixando os convênios privados somente com os dividendos, sem contrapartidas compensatórias. O sistema público de saúde fica, portanto, com o ônus das doenças mais graves e dos idosos, tendo em vista que as contribuições aos planos de saúde particulares aumentam com o decorrer da idade. A lógica implacável do mercado incompatibiliza lucro e necessidade social. ${ }^{7}$ Para a maior parte da população que necessita do serviço público, resta enfrentar filas e muito descaso, apesar dos esforços do corpo profissional. A estrutura de hierarquização dos serviços de saúde reconhecida mundialmente (Brasil, 2006), que vai do atendimento preventivo aos casos raros, fica comprometida quando existem rupturas importantes em algum elo da cadeia. A falta ou a precariedade de postos locais e do atendimento básico que não conseguem suprir a demanda da população, acaba sobrecarregando os hospitais com casos imediatos e banais, prejudicando todo o

6 O sociólogo francês Benjamin Moignard fez uma pesquisa comparando uma escola periférica francesa com uma escola da favela da Rocinha no Rio de Janeiro, que vai dar origem ao livro "A Escola e a Rua - Fábricas de Delinqüência" (PUF, 2008).

7 A lei 8.080/1990 que dispõe sobre a Política Nacional de Saúde, define que a iniciativa privada poderá participar do Sistema Único de Saúde - SUS, em caráter complementar, o que acaba não ocorrendo. Devido à precariedade do sistema público, os serviços privados passam a ser essenciais e a possibilidade de sobrevivência, na dependência da razão de mercado. 
funcionamento do sistema. ${ }^{8}$ Os programas de agentes comunitários, as pastorais de saúde, o atendimento em instituições de ensino, em especial nos hospitais das universidades públicas, tentam suprir as lacunas deixadas pelo Ministério da Saúde e pelas redes de saúde municipais.

Um dos maiores problemas nos países subdesenvolvidos continua sendo o das condições sanitárias, implicando na promoção das doenças e epidemias, cuja resolução poderia aliviar o peso sobre o sistema médico-hospitalar. No Brasil, quase a metade dos domicílios não dispõe de rede de coleta e tratamento de esgoto (IBGE, 2007) (Quadro 3). "O acesso a esse serviço avançou de forma pífia nos últimos 14 anos, atravessando quatro diferentes gestões federais ao ritmo de 1,59\% ao ano. Mantida essa velocidade, para reduzir à metade o déficit de saneamento básico seriam necessários 56 anos e meio, segundo cálculos da Fundação Getúlio Vargas (FGV)" (Neri, 2007).

QUADRO 3 | Domicílios com acesso a abastecimento de água e esgotamento sanitário, 2007

\begin{tabular}{|c|c|c|c|c|c|c|c|c|}
\hline \multicolumn{3}{|c|}{ ÁGUA } & \multicolumn{6}{|c|}{ SANEAMENTO } \\
\hline & \multirow{2}{*}{\begin{tabular}{|c|} 
REDE GERAI \\
$(\mathrm{mil})$
\end{tabular}} & \multirow[t]{2}{*}{$\%$} & \multicolumn{2}{|c|}{$\begin{array}{c}\text { REDE } \\
\text { COLETORA }\end{array}$} & \multicolumn{2}{|c|}{$\begin{array}{c}\text { FOSSA } \\
\text { SÉPTICA }\end{array}$} & \multicolumn{2}{|l|}{ OUTRO } \\
\hline & & & \multicolumn{2}{|l|}{$(\mathrm{mil})$} & \multicolumn{2}{|l|}{$(\mathrm{mil})$} & \multicolumn{2}{|l|}{ (mil) } \\
\hline Brasil & 46.943 & 83,3 & 28.921 & $51,30 \%$ & 12.558 & $22.3 \%$ & 14.865 & $26,40 \%$ \\
\hline Norte & 2.179 & 55,9 & 381 & $9,80 \%$ & 1.754 & $45,00 \%$ & 1.766 & $45,30 \%$ \\
\hline Nordeste & 10.792 & 75,7 & 4.277 & $29,70 \%$ & 3.619 & $25,40 \%$ & 6.405 & $44,90 \%$ \\
\hline Sudeste & 23.077 & 91,8 & 19.961 & $79,40 \%$ & 2.514 & $10,00 \%$ & 2.677 & $10,70 \%$ \\
\hline Sul & 7.533 & 84.8 & 2.905 & $32.7 \%$ & 4.153 & $46,80 \%$ & 1.821 & $20,50 \%$ \\
\hline $\begin{array}{l}\text { Centro- } \\
\text { Oeste }\end{array}$ & 3.362 & 80,8 & 1.448 & $34,80 \%$ & 518 & $12,40 \%$ & 2.197 & $52,80 \%$ \\
\hline
\end{tabular}

fonte Organizado a partir de IBGE (Pesquisa Nacional de Amostra de Domicílios-PNAD), 2007.

A localização, renda per capita, educação da mãe e/ou do pai, gênero, presença de pais e de irmãos são as variáveis que, nessa ordem, têm maior incidência nas oportunidades de acesso ao saneamento (Barros et al., 2008). A cidade representa,

8 O Art. $6^{\circ}$ do Programa de Atenção Básica do Ministério da Saúde que, apesar das divisōes das competências entre Governo Federal, Estados e Municípios, cabe ao Ministério da Saúde a análise das metas e de sua efetividade, implicando, inclusive, na liberação dos recursos (Brasil, 1999). 
assim, o segundo fator de agravamento da pobreza. À desigual distribuição da renda acrescenta-se a falta de equipamentos e serviços públicos, diferenciando ainda mais as chances sociais, seja pelas diferenças regionais, seja pela posição que se ocupa dentro da própria estrutura urbana.

\section{Brasil, um país de oportunidades?}

"E ainda que a raça, gênero, e lugar de residência tenham tido um papel, nenhuma circunstância teve tanto peso como a educação de sua mãe e os ingressos de seu pai. Em outras palavras, os latino-americanos têm razão de se sentir desfavorecidos por um terreno onde o jogo não está nivelado, porque de fato não está” (Giugale, 2008).

Os diferentes governos brasileiros sempre assumiram o discurso do progresso, passando a idéia de que o país estaria melhorando constantemente, como se isso abarcasse a totalidade da nação. A história seria uma linha contínua, bastava ir sempre em frente que as populações estariam avançando em direção à melhoria da qualidade de vida. No entanto, pesquisas recentes patrocinadas pelo Banco Mundial desmentem, rapidamente, os discursos promissores. Se forem analisados os índices de oportunidades humanas para educação e habitação, o Brasil tem que reconhecer que não há muito do que se vangloriar. $\mathrm{O}$ Índice de Oportunidades $\mathrm{Hu}$ manas $(\mathrm{IOH})$ constitui-se no conjunto de oportunidades relacionadas à educação (sexta série na época e assistência escolar para crianças entre 10 e 14 anos) e habitação (acesso a água potável, saneamento e eletricidade). "O nível de oportunidade medido por esse índice pode ser interpretado como o número de oportunidades existentes em dada sociedade, tomando-se como base o princípio da igualdade de oportunidades" (Barros et al., 2008, p.81).

Considerando-se o $\mathrm{IOH}$ total, os resultados mostram que Argentina, Chile, Costa Rica, Uruguai e Venezuela estão mais próximos da universalidade em relação às necessidades que foram consideradas essenciais à qualidade de vida urbana. Honduras, Guatemala e Nicarágua estão mais distantes dessa meta devido à baixa cobertura e também porque a atual cobertura não está distribuída equitativamente (Quadro 4). Se o Brasil aparece um pouco acima da média para os índices relativos à habitação, isso se deve à extensão do abastecimento de água e aos serviços de eletricidade, que compensam os baixos níveis de saneamento analisados. Nos requisitos relativos à educação, o Brasil fica bem abaixo da maior parte dos países da América Latina e Caribe, com valores superiores somente a Guatemala, El Salvador e Honduras, países que têm renda per capita (U\$ 5.400; U\$ 5.200 e U\$ 3.300, respectivamente) bem inferior ao Brasil (U\$ 9.700 em 2008).

Além de apresentar médias gerais extremamente baixas relativas à educação, a situação brasileira vê-se agravada pelas desigualdades internas de oportunidades entre os diferentes grupos sociais. Isso pode ser verificado a partir do Índice $D$, uma medida de desigualdade de oportunidades, que "é uma versão do índice de dissimilaridade amplamente utilizado na sociologia e aplicado aos resultados dicotômicos" 
(Barros et al., 2008, p. 96). O indice D mede quão desiguais são as taxas de acesso a um serviço para grupos definidos por características de circunstâncias (por exemplo, localização, gênero, educação dos pais, etc.), comparadas com taxas médias de acesso ao mesmo serviço para o conjunto da população. "Em uma situação de igualdade de oportunidade, "D” será zero" (Barros et al., 2008, p. 91).

QUADRO 4 | Índice de Oportunidades Humanas

\begin{tabular}{|c|c|c|c|}
\hline & IOH PARA EDUCAÇÃO & IOH PARA HABITAÇÃO & $\begin{array}{c}\text { ÍNDICE DE OPORTUNIDADES } \\
\text { HUMANAS }\end{array}$ \\
\hline Chile & 90 & 93 & 91 \\
\hline Argentina & 89 & 88 & 88 \\
\hline Costa Rica & 74 & 94 & 86 \\
\hline Venezuela & 84 & 89 & 86 \\
\hline Uruguai & 85 & 85 & 85 \\
\hline México & 88 & 75 & 82 \\
\hline Colômbia & 76 & 69 & 74 \\
\hline Equador & 80 & 74 & 74 \\
\hline Jamaica & 90 & 55 & 73 \\
\hline Brasil & 67 & 77 & 72 \\
\hline República Dominicana & 77 & 65 & 71 \\
\hline Panamá & 81 & 57 & 69 \\
\hline Paraguai & 74 & 59 & 67 \\
\hline Perú & 83 & 49 & 66 \\
\hline Bolivia & 83 & 48 & 62 \\
\hline El Salvador & 65 & 46 & 55 \\
\hline Honduras & 62 & 44 & 53 \\
\hline Guatemala & 51 & 50 & 50 \\
\hline Média* & 76 & 64 & 70 \\
\hline
\end{tabular}

Pesquisa REALIZAda COM 200 Milhốes de CRIANÇAS ENTRE 0 E 16 ANOS DE 19 PaÍseS da América Latina e do Caribe. (*) Média restrita aos países analisados. FONTE BARRos E OUTROS, 2008, P. 110.

$\mathrm{Na}$ América Latina e Caribe, as taxas de assistência escolar para crianças entre 10 e 14 anos de idade mostram baixos níveis de desigualdade de oportunidades. Todos os países, com exceção de Honduras, têm um Índice D inferior a $5 \% \mathrm{em}$ 2005, ou seja, $5 \%$ ou menos do total das oportunidades disponíveis constituem a diferença de oportunidades do setor entre os diferentes grupos sociais (Quadro 5). Este nível de desigualdade está associado aos altos níveis de cobertura, às vezes universais, que foram alcançados na região desde meados dos anos 1990. 
QUADRO 5 | Desigualdade de oportunidades (Índice D) em educação, 2005

\begin{tabular}{|c|c|c|}
\hline PAÍsES & $\begin{array}{l}\text { SEXTA SÉRIE NO } \\
\text { TEMPO (\%) }\end{array}$ & $\begin{array}{c}\text { ASSISTÊNCIA ESCOLAR } \\
(\%)\end{array}$ \\
\hline Jamaica & 2 & 1 \\
\hline Chile & 3 & 0 \\
\hline Argentina & 3 & 1 \\
\hline México & 5 & 2 \\
\hline Venezuela & 6 & 1 \\
\hline Bolívia & 7 & 2 \\
\hline Uruguai & 7 & 2 \\
\hline Equador & 7 & 5 \\
\hline Panamá & 8 & 3 \\
\hline Peru & 9 & 2 \\
\hline Costa Rica & 9 & 2 \\
\hline Colômbia & 11 & 3 \\
\hline Paraguai & 11 & 3 \\
\hline Rep. Dominicana & 12 & 1 \\
\hline El Salvador & 15 & 4 \\
\hline Honduras & 17 & 7 \\
\hline Brasil & 20 & 1 \\
\hline Nicarágua & 24 & 4 \\
\hline Guatemala & 27 & 5 \\
\hline Média & 11 & 3 \\
\hline
\end{tabular}

FONTE BARros E OUtros, 2008, P.97.

A média do índice “D” em 2005 para os 19 países considerados em relação a oportunidades educativas, tendo como critério a conclusão da $6^{a}$ série no tempo correto, é de $11 \%$, o que significa que há $11 \%$ de diferença de oportunidades das crianças terminarem a $6^{\text {a }}$ série no devido tempo. O grau de desigualdade de oportunidades varia consideravelmente entre os países da região, de 3\% a mais de $20 \%$ como no caso do Brasil, Nicarágua e Guatemala. Em 2005, o Brasil apresenta o terceiro pior desempenho em termos de oportunidades de acesso entre grupos sociais $(20 \%)$, perdendo somente para a Nicarágua (24\%) e Guatemala (27\%) em termos de sexta série no tempo correto. Esses três países ficam muito distantes da média regional (11\%), ou seja, todos os demais conseguiram, com um volume menor de riqueza gerada, propiciar condições mais igualitárias em termos de oportunidades educacionais. 
A pobreza no país continua a afetar com muito mais intensidade as crianças e adolescentes. Em 2007, 30,0\% dos brasileiros viviam com rendimento familiar mensal de até $1 / 2$ salário mínimo per capita. No caso dos domicílios com crianças e adolescentes de 0 a 17 anos, essa proporção sobe para 46\%. Chama mais atenção ainda o percentual de domicílios com rendimento familiar mensal de até $1 / 4$ de salário mínimo e com crianças, que chega a 19,6\%. Em contrapartida, apenas 1,7\% desse segmento da população vivia com rendimento familiar de mais de 5 salários mínimos per capita (IBGE, 2008).

Apesar das melhoras nas condições de vida da população, ainda é baixo o número de domicílios com crianças de até 6 anos de idade que possuem condições adequadas de saneamento. ${ }^{3}$ Em 2007, apenas 54,5\% dos domicílios com crianças possuíam todos os serviços de saneamento simultaneamente. Há, no entanto, uma grande desigualdade em termos de acessibilidade ao saneamento conforme o rendimento familiar. Nos domicílios com renda familiar abaixo de $1 / 2$ salário mínimo per capita com crianças, somente $38,4 \%$ encontra condições adequadas de saneamento, enquanto nos domicílios das famílias com rendimento familiar de mais de cinco salários mínimos esse índice alcança 70,3\% (IBGE, 2008). Este dado é relevante tendo em vista que boa parte dos óbitos infantis tem causas ligadas à falta de saneamento básico, como, por exemplo, a diarréia. Portanto, a melhora do nível de saneamento tem impacto direto sobre as taxas de mortalidade infantil.

Os dados referentes à população brasileira, sobretudo de idosos e crianças, denotam a fragilidade da proteção social no Brasil. Em 2007, poderiam ser considerados em situação de pobreza mais de 2,5 milhões de idosos (12,2\%) no país, que viviam em domicílios cujo rendimento médio mensal domiciliar per capita era de até $1 / 2$ salário mínimo, com maior incidência nas zonas rurais e na região Nordeste. $\mathrm{O}$ maior contraste urbano/rural ocorria na região Sudeste $(6,8 \% / 16,1 \%)$, e o menor na Região Sul (6,3\%/7,1\%). Em contrapartida, considerando a faixa de rendimento mensal domiciliar de mais de 2 salários-mínimos per capita, a proporção de idosos nas áreas urbanas $(26,5 \%)$ era mais de três vezes superior a da área rural $(8,1 \%)$ (IBGE, 2008). Muitos desses idosos são responsáveis por grande parte da renda domiciliar, demonstrando uma degradação intergeracional das condições de vida. Em $53 \%$ dos domicílios com idosos, eles são responsáveis por mais da metade da renda familiar, sendo esta situação ainda mais expressiva no Nordeste $(63,5 \%$ dos domicílios). Os benefícios outorgados pelo sistema de proteção social, ainda que precários e em processo de deterioração, servem de suporte à manutenção das famílias. Em 2007, 84,4\% dos 13,8 milhões de idosos com 65 anos ou mais recebiam aposentadoria e/ou pensão, proporção esta já alcançada em 1997, ou seja, em dez anos, não houve qualquer melhoria que pudesse aliviar o peso sobre os rendimentos dos idosos. Ao contrário, 22,5\% dos idosos acima de 65 anos (cerca de 3,1 milhões de pessoas) continuavam trabalhando em 2007 , sendo que a grande maioria $(74,7 \%)$ era composta de aposentados. $\mathrm{Na}$ área rural, estes percentuais eram 46,9\% e 84,9\% e na área urbana representavam 17,6\% e 70\% (IBGE, 2008). 
Assim, num período de reprodução das desigualdades sociais, com o rebaixamento geral de salários, desemprego, intermitência e instabilidade das relações de trabalho, diminuição dos direitos trabalhistas e sociais, os idosos representam as antigas condições de emprego e renda, herança de um tempo em que a proteção social ainda reconhecia alguns direitos aos trabalhadores e às suas famílias. O fato das famílias dependerem das aposentadorias e da reinserção dos mais velhos no mercado de trabalho demonstra, também, como se fecham as oportunidades para as novas gerações, tanto em termos de renda como de acesso ao trabalho e aos serviços urbanos.

As desigualdades de oportunidades indicam que o caminho que vem sendo percorrido não conduz a uma sociedade mais igualitária. As políticas assistencialistas, de caráter imediato, não podem ser consideradas como substitutivas da constituição de uma sociedade baseada em direitos universais. Nesse sentido, caminhamos para trás. Resta considerar que a pobreza dos adultos decorre, em grande parte, das oportunidades dadas na infância. Entre um quarto (Colômbia) e a metade (Guatemala) da desigualdade de renda dos adultos na América Latina se deve às circunstâncias que enfrentaram no início da vida, sem que tivessem contribuído para que assim ocorresse (Giugale, 2008).

\section{Considerações finais}

Frente aos interesses das grandes corporações internacionais, somente Estados Nacionais com projetos próprios poderiam apresentar alternativas à lógica mercantil do processo de acumulação visando estabelecer políticas socialmente protecionistas. $\mathrm{O}$ Brasil caminha, no entanto, em sentido inverso, reforçando perversidades sociais em prol da subserviência aos interesses financeiros internacionais, da concentração de capitais e do surgimento de novas classes enriquecidas no cenário nacional (Oliveira, 2003). A "financeirização" do Estado impôs à grande parcela da população enormes sacrifícios econômicos e sociais no sentido de saldar uma dívida externa que nunca será paga nos termos em que está colocada (Sader, 2002). A política econômica de juros elevados, visando captar investimentos de curto prazo para promover o superávit primário e financiar o agro-business, ao mesmo tempo em que distancia o país em relação aos novos setores de inovação - baseados na ciência como força produtiva direta (Braverman, 1981)-, promove uma polarização das classes sociais a partir de um acelerado processo de ampliação da desigualdade social. Somando-se à precariedade histórica, o abandono ou a privatização dos serviços públicos acompanha o novo ciclo de desemprego explícito ou dissimulado, fazendo com que o Estado contribua para o reforço da pobreza e da exclusão estrutural e conjuntural. Assim, sem contar com as condições mínimas de proteção social, a população brasileira vê-se num movimento de empobrecimento acelerado, o que vem explicar o processo cada vez mais longínquo de periferização e a densificação dos assentamentos irregulares, sobretudo após a década de 1990, nas grandes cidades brasileiras.

O Estado volta-se, assim, contra a elevação do nível geral de vida e a possibilidade da participação mais igualitária nos rendimentos do trabalho. Contribuindo 
para a concentração da riqueza em setores privilegiados ${ }^{9}$, estabelecidos a partir da inserção submissa na nova divisão internacional do trabalho, o Estado brasileiro sacrifica as possibilidades de acesso aos requisitos elementares de construção de uma sociedade saudável, educada e consciente. Enquanto a minoria mais rica vê crescer exponencialmente sua participação na renda nacional, grandes porções das classes médias juntam-se à ampliação dos setores de pobreza, num modelo de crescimento que, baseado em exportações de commodities, prescinde de um mercado interno dinâmico, ao mesmo tempo em que oferece como vantagem comparativa a degradação do trabalho. Como se falar em diminuição de desigualdades sociais quando o salário mínimo nacional tende a valores cada vez mais desfavoráveis em relação aos demais países, os níveis de desemprego são elevados e a proteção social praticamente inexistente? Enquanto a remuneração do sistema financeiro coloca cada vez mais os bancos nacionais entre os mais bem sucedidos do mundo, grandes parcelas da população devem se contentar com a reprodução tendencialmente negativa das condições de vida, amainada por uma soma de recursos que, na melhor das hipóteses, evita a degradação absoluta. Os esboços de programas de reciclagem ou de reinserção da força de trabalho, únicos capazes de romper o circuito da dependência dos favores pretensamente estatais, ficaram sem recursos. A conciliação entre as rivalidades sociais pretende ser realizada a partir da construção da imagem de liderança carismática unificadora, acima das práticas reais e das evidências sociais (Gullar, 2008). Se os dados da realidade apresentamse de forma pouco defensável, coloca-se, então, a necessidade da construção de uma segunda versão, o que requer a administração científica da informação. Estabelece-se, assim, uma cumplicidade com os grupos econômicos que controlam os meios de comunicação, que passam a ter um papel estratégico na elaboração do ideário cultural nacional.

A impossibilidade do Estado de gerar estruturas de inserção abre um enorme fosso social, onde o diálogo cede lugar à única forma de participação que a sociedade estabelecida legou as gerações de excluídos: a violência cotidiana. Violência derivada de um sistema cuja lógica de acumulação baseia-se na expropriação imposta pela legitimidade da força e do monopólio da repressão atribuído ao Estado. Ao endosso explícito dos sucessivos governos brasileiros à violência da moeda (Aglietta \& Orlean, 1982) corresponde a pauperização da população rural e urbana, com o desemprego, a precarização do trabalho e o aumento do setor informal para aqueles que vislumbram alguma possibilidade de inserção social, mesmo que frágil e instável. Aos outros, a reprodução contínua da exclusão.

A paisagem retratará, de forma elucidativa, os movimentos populacionais e a expansão dos assentamentos precários, plasmando, sobre o espaço, a ruptura acentuada entre as classes e seu conseqüente "apartheid" social. A polarização das classes sociais faz conviver locais de representação da sofisticação supérflua com a extensão da banalização da reprodução da vida. A metrópole transforma-se em

O Estado promove, inclusive, o aparecimento de novas classes enriquecidas, ligadas diretamente às políticas instituídas, ou mesmo, aos setores governamentais (Oliveira, 2003). 
seu contrário. De veículo de penetração de inovações e de crescimento cultural transforma-se em cenário do medo e do antagonismo social. IEURE

\section{Referências bibliográficas}

Aglietta, M. \& Orlean, A. (1982). La Violence de la Monnaie. Paris: PUF.

Barros, R. P.; Ferreira, F. H. G.; Vega J. R. M. \& Chanduvi, J. S. (2008). Midiendo la Desigualdad de Oportunidades en América Latina y el Caribe. Washington: Banco Mundial.

Batista Júnior, P. N. (2000). O que impede o Brasil de crescer mais. Folha de São Paulco, 19 de outubro de 2000, p. B-2.

Beisegel, C. de R. (1984). Educação e Sociedade no Brasil após 1930. En B. Fausto (Ed.). História Geral da Civilização Brasileira. O Brasil Republicano (1930-1964). São Paulo: Difel.

Boal, A. (2002). Síndrome de Raskolnikov. Folha de São Paulo, 23 de janeiro.

Bolaffi, G. (1982). Habitação e Urbanismo: o problema e o falso problema. In E. Maricato (Ed.). $A$ produção capitalista da casa (e da cidade). São Paulo: Alphaomega.

Brasil. Ministério da Educação. Casa Civil (1996). Lei de Diretrizes e Bases da Educação. Brasília: Ministério da Educação.

Brasil. Ministério da Saúde (1999). Programa de Atenção Básica. Brasília: Ministério da Saúde.

Brasil. Ministério da Saúde (2006). Politica Nacional de Promoção da Saúde. Brasília: Ministério da Saúde.

Braverman, H. (1981). Trabalho e Capital Monopolista. Rio de Janeiro: Zahar Editores.

Carone, E. (1974). A Segunda República. São Paulo: Difel.

Castro, A. (2000). Mais abertura, vamos discutir. Folha de São Paulo, 11 de outubro.

Castro, A. (2000b). Além da fabricação. Folha de São Paulo, 9 de agosto.

Davis, M. (2006). Planeta favela. São Paulo: Boitempo.

Fausto, B. (Ed.) (1978). História Geral da Civilização Brasil. O Brasil Republicano. Vol. III. São Paulo: Difel.

Giugale, M. M. (2008). La igualdad de oportunidades: um nuevo paradigma de desarrollo. Banco Mundial. Gullar, F. Palmas para Lula. Folha de São Paulo, 28 de setembro.

Harvey, D. (1989). Condição Pós-Moderna. São Paulo: Ediçôes Loyola.

Ibge (2008). PNAD 2007. Comunicação Social, 18 de setembro.

Ibope \& Instituto Paulo Montenegro (2007). Indicador de analfabetismo funcional - INAF.

IBGE (2008). Sintese de Indicadores Sociais. Comunicação Social, 24 de setembro.

Lafore, R. (1999). Services Publics Sociaux et Cohesion Sociale. Service Public et Lien Social. Paris: Editions L'Harmattanp.

Merrien, F. X. (1997). L'Etat-Providence. Paris: PUF.

Moignard, B. (2008). Os escolados. Entrevista concedida à Leneide Duarte-Plon. Folha de São Paulo, 05 de outubro.

Neri, M. (2007). Metade do Brasil não tem esgoto, diz FGV. Entrevista concedida à Folha de São Paulo, 23 de setembro.

Oliveira, F. (1972). A Economia Brasileira: Crítica à Razão Dualista. São Paulo: Novos Estudos Cebrap.

Oliveira. F. (1982). O Estado e o urbano no Brasil. Espaço \& Debates. No. 6, jun/set, p. 36-54.

Oliveira, F. (2003). Critica à Razão Dualista - O Ornitorrinco. São Paulo: Boitempo. 
Pochmann, M. (2004). Proteção Social na Periferia do Capitalismo: Considerações sobre o Brasil. Perspectiva. Vol.18, No. 2.

Rangel, I. (1982). Ciclos, Tecnologia e Crescimento. Rio de Janeiro: Civilização Brasileira.

Sader, E. (2002). Sair da financeirização. Folha de São Paulo, 21 de janeiro.

Santos, M. (1979). O Espaço Dividido: os dois Circuitos da Economia Urbana dos Países Subdesenvolvidos. Rio de Janeiro: Francisco Alves.

Santos, M. (1991). A Revolução Tecnológica e o Território: Realidades e Perspectivas. Terra Livre, No. 9, julho-dezembro. São Paulo: AGB.

Santos, M. (1994). O Retorno do Território. En M. Santos, M.A. Souza \& M.L. Silveira (Eds.). Território, Globalização e Fragmentação. São Paulo: Hucitec/Anpur.

Tavares, M. (1981). Da Substituição de Importações ao Capitalismo Financeiro. Rio de Janeiro: Zahar.

Tavares, M. (1985). Acumulação de Capital e Industrialização no Brasil. Campinas: Unicamp.

Tavares, M. (1999). Destruição não-criadora: memórias de um mandato popular contra a recessão, o desemprego e a globalização subordinada. Rio de Janeiro: Record.

Tavares, M. (2000). Desnacionalização e vulnerabilidade externa. Folha de São Paulo, 3 de dezembro.

Tavares, M. (2001). Transformação social como eixo do desenvolvimento. Folha São Paulo, 04 de novembro.

Tiezzi, R (2008). Brasil Analfabetizado. Geração Editorial, 26 de outubro.

Trotsky, L. (2007). A Revolução Permanente. São Paulo: Editora Expressão Popular.

Veblen, T. (1970). Théorie de la classe de loisir. Paris: Editions Gallimard. 